\title{
The noctilucent cloud (NLC) display during the ECOMA/MASS sounding rocket flights on 3 August 2007: morphology on global to local scales
}

\author{
G. Baumgarten ${ }^{1}$, J. Fiedler ${ }^{1}$, K. H. Fricke ${ }^{2}$, M. Gerding ${ }^{1}$, M. Hervig ${ }^{3}$, P. Hoffmann ${ }^{1}$, N. Müller ${ }^{1}$, P.-D. Pautet ${ }^{4}$, \\ M. Rapp ${ }^{1}$, C. Robert $^{5}$, D. Rusch ${ }^{6}$, C. von Savigny ${ }^{5}$, and W. Singer ${ }^{1}$ \\ ${ }^{1}$ Leibniz-Institut für Atmosphärenphysik e. V., 18225 Kühlungsborn, Germany \\ ${ }^{2}$ Physikalisches Institut der Universität Bonn, 53115 Bonn, Germany \\ ${ }^{3}$ GATS, Inc., Driggs, Idaho, 83422, USA \\ ${ }^{4}$ Utah State University, Center for Atmospheric and Space Sciences, Logan UT, 84322-4405, USA \\ ${ }^{5}$ Institut für Umweltphysik der Universität Bremen, 28359 Bremen, Germany \\ ${ }^{6}$ Laboratory for Atmospheric and Space Physics, University of Colorado, Boulder, CO 80303, USA
}

Received: 16 October 2008 - Revised: 5 February 2009 - Accepted: 5 February 2009 - Published: 2 March 2009

\begin{abstract}
During the ECOMA/MASS rocket campaign large scale NLC/PMC was observed by satellite, lidar and camera from polar to mid latitudes. We examine the observations from different instruments to investigate the morphology of the cloud. Satellite observations show a planetary wave 2 structure. Lidar observations from Kühlungsborn $\left(54^{\circ} \mathrm{N}\right)$, Esrange $\left(68^{\circ} \mathrm{N}\right)$ and $\operatorname{ALOMAR}\left(69^{\circ} \mathrm{N}\right)$ show a highly dynamic NLC layer. Under favorable solar illumination the cloud is also observable by ground-based cameras. The cloud was detected by cameras from Trondheim $\left(63^{\circ} \mathrm{N}\right)$, Juliusruh $\left(55^{\circ} \mathrm{N}\right)$ and Kühlungsborn. We investigate planetary scale morphology and local scale gravity wave structures, important for the interpretation of the small scale rocket soundings. We compare in detail the lidar observations with the NLC structure observed by the camera in Trondheim. The ALOMAR RMR-lidar observed only a faint NLC during the ECOMA launch window, while the camera in Trondheim showed a strong NLC display in the direction of ALOMAR. Using the high resolution camera observations $(t \sim 30 \mathrm{~s}, \Delta x<5 \mathrm{~km})$ and the wind information from the meteor radar at ALOMAR we investigate the formation and destruction of NLC structures. We observe that the NLC brightness is reduced by a factor of 20-40 within 100 s which can be caused by a temperature about $15 \mathrm{~K}$ above the frostpoint temperature. A horizontal temperature gradient of more than $3 \mathrm{~K} / \mathrm{km}$ is estimated.
\end{abstract}

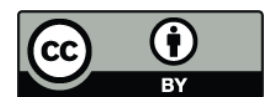

Correspondence to: G. Baumgarten (baumgarten@iap-kborn.de)
Keywords. Atmospheric composition and structure (Cloud physics and chemistry; Middle atmosphere - composition and chemistry; Instruments and techniques) - Meteorology and atmospheric dynamics (Middle atmosphere dynamics)

\section{Introduction}

Noctilucent clouds (NLC), also called Polar Mesospheric Clouds (PMC) when observed from space, allow a detailed study of the atmosphere at altitudes close to the mesopause where remote sensing is challenging (e.g. Thomas, 1984). Since the extensive studies of noctilucent clouds by visual methods from ground at the end of the 19th century (Jesse, 1889), several remote sensing methods from ground and space as well as in-situ methods have been developed to investigate the nature of the clouds. The different methods address different aspects of the clouds and allow to study NLC from global to local scales (e.g. Gadsden and Schröder, 1989; Kirkwood et al., 2002; Dalin et al., 2009; DeLand et al., 2006). We present the first combined analysis from different observation platforms to put the results from a sounding rocket campaign at the Andøya rocket range $\left(69^{\circ} \mathrm{N}\right)$ in a broader perspective. From 1 August to 15 August 2007 there was a combined rocket campaign to launch the MASS and the ECOMA payloads. The payloads were launched in two salvos, the first on 3 August and the second on 6 August. During the first salvo noctilucent clouds were observed by camera and lidar from ground at three different locations from nearby the launch site to about $1700 \mathrm{~km}$ south

Published by Copernicus Publications on behalf of the European Geosciences Union. 
at Kühlungsborn $\left(54^{\circ} \mathrm{N}\right)$. On 3 August 2007, two rockets were launched, the first one was the MASS payload which penetrated the NLC layer at about 22:53 UT and the second one the ECOMA payload at about 23:23 UT (Robertson et al., 2009; Rapp et al., 2009). We present results from several space-based instruments observing PMC in the UV and the IR spectral range, ground based camera, lidar and radar instruments. The instruments are described in Sect. 2 and Sect. 3 summarizes the observations.

\section{Instruments and method}

\subsection{Satellites}

\subsubsection{SCIAMACHY}

SCIAMACHY (SCanning Imaging Absorption spectroMeter for Atmospheric CHartographY) is one of the 10 instruments aboard Envisat observing the Earth since March 2002 in a sun-synchronous orbit, with a descending equatorial crossing time of 10:00 LT. SCIAMACHY observes the NLC scattered sunlight in limb geometry at wavelengths between 265 and $300 \mathrm{~nm}$ (channel 1), with a spectral resolution of $0.24 \mathrm{~nm}$. The instrument scans the atmosphere in $3.3 \mathrm{~km}$ steps and every measurement samples a volume of about $500 \mathrm{~km}$ in viewing direction, $3 \mathrm{~km}$ of vertical extent and $960 \mathrm{~km}$ across viewing direction. SCIAMACHY observes a peak in radiance around $80 \mathrm{~km}$ when a NLC is in the field of view (FOV), and using the radiance observed below and above the NLC, the net contribution of the NLC scattering to the total radiance can be calculated for different wavelengths (von Savigny et al., 2004).

\subsubsection{CIPS}

The Cloud Imaging and Particle Size experiment (CIPS) on board the AIM satellite is a downward looking panoramic imager with a field of view of $120^{\circ}$ (along-track) by $80^{\circ}$ (across-track) or about $2000 \times 1000 \mathrm{~km}$; it is described in more detail by Russell III et al. (2009) and McClintock et al. (2009). CIPS has an unprecedented spatial resolution of $\sim 2 \times 2 \mathrm{~km}$ in the nadir. In order to derive the PMC morphology and cloud particle size, CIPS measures scattered sunlight with a $15 \mathrm{~nm}$ passband centered at $265 \mathrm{~nm}$. The observed signals include Rayleigh scattering by molecules as well as scattering by the PMC particles. The Rayleigh scattering signal must therefore be separated from the observed signal to infer PMC. This background signal comes from altitudes above $50 \mathrm{~km}$. We show level $3 \mathrm{~A} \mathrm{~V} 3.11$ data retrieved from the AIM webpage (http://aim.hampton.edu).

\subsubsection{SOFIE}

SOFIE is a solar occultation instrument on board the AIM satellite to measure vertical profiles of limb path atmospheric transmission within 16 spectral bands between 0.29 and $5.32 \mu \mathrm{m}$ wavelength (Gordley et al., 2009). SOFIE observes about 15 sunsets in the Southern Hemisphere and 15 sunrises in the Northern Hemisphere each day. Measurement latitude coverage ranges from about $65^{\circ}$ to $80^{\circ}$ north or south. SOFIE measurements are used to retrieve PMC extinction, at eleven wavelengths from 0.330 to $5.01 \mu \mathrm{m}$. In addition to temperature and the abundance of gaseous species, PMC are measured by monitoring the attenuation of solar radiation using broadband radiometers. The SOFIE field of view is about $1.5 \mathrm{~km}$ vertical $\times 4.3 \mathrm{~km}$ horizontal. Detectors are sampled at $20 \mathrm{~Hz}$ which corresponds to $\sim 145 \mathrm{~m}$ vertical spacing. The sample volume length, as defined by the line-of-sight entrance and exit of a spherical shell with vertical thickness of the FOV, is $\sim 290 \mathrm{~km}$.

\subsection{Lidars}

We use data from three middle atmosphere lidars to characterize NLC at different locations, namely from the ALOMAR Rayleigh/Mie/Raman (RMR) lidar at Andøya/Norway $\left(69^{\circ} \mathrm{N}, 16^{\circ} \mathrm{E}\right)$, the Bonn University RMR lidar at Esrange/Sweden $\left(68^{\circ} \mathrm{N}, 21^{\circ} \mathrm{E}\right)$, and the IAP RMR lidar at Kühlungsborn/Germany $\left(54^{\circ} \mathrm{N}, 12^{\circ} \mathrm{E}\right)$. These systems are active remote sensing instruments measuring relative density profiles and particle (aerosol) properties in the stratosphere and mesosphere. They are optimized to operate at $532 \mathrm{~nm}$ which is the second harmonic of the Nd:YAG lasers used in the transmitters. The detectors record single photons emitted by the laser and backscattered from air molecules and NLC particles as a function of altitude as well as sunlight scattered by the atmosphere. After subtraction of the solar background an altitude profile of the total backscatter signal is obtained. From that the aerosol volume backscatter coefficient is calculated, which is a measure for the NLC brightness.

The different NLC detection capabilities of the lidar systems as well as their operation modes during the ECOMA campaign are shortly described below. The ALOMAR RMR lidar is a twin system with two $1.8 \mathrm{~m}$ diameter steerable telescopes. It utilizes a combination of strong spatial and spectral filtering to obtain full daylight capability, which is attained by a very small telescope field-of-view of $180 \mu \mathrm{rad}$ and narrow band (4-10 pm) capacitance stabilized etalons (von Zahn et al., 2000). As a result NLC can be detected during all local times of the Arctic summer (e.g. Fiedler et al., 2004). Using the backscatter at all three emitted laser wavelengths $(1064 \mathrm{~nm}, 532 \mathrm{~nm}$ and $355 \mathrm{~nm})$, the size, distribution width and number density of aerosol and NLC particles are calculated (Baumgarten et al., 2008; Baumgarten and Fiedler, 2008). Throughout the ECOMA campaign the lidar was operated with a range resolution of $50 \mathrm{~m}$ and a temporal resolution of about $30 \mathrm{~s}$. One of the telescopes was pointed towards the specified rocket trajectory, while the other was adjusted vertically. This setup allows to investigate the horizontal structure of the NLC layer (Baumgarten et al., 2002). 
Table 1. Cameras of the IAP NLC Camera Network: latitude, longitude, altitude and pointing of the cameras. The field of view of the cameras is about $54^{\circ}$ horizontally and $40.5^{\circ}$ vertically.

\begin{tabular}{lrrrrr}
\hline Location & $\begin{array}{r}\text { Lat. } \\
{\left[{ }^{\circ}\right]}\end{array}$ & $\begin{array}{r}\text { Long. } \\
{\left[{ }^{\circ}\right]}\end{array}$ & $\begin{array}{r}\text { Altitude } \\
{[\mathrm{m}]}\end{array}$ & $\begin{array}{r}\text { Az. } \\
{\left[{ }^{\circ}\right]}\end{array}$ & $\begin{array}{r}\text { El. } \\
{\left[{ }^{\circ}\right]}\end{array}$ \\
\hline Trondheim & 63.4 & 10.41 & 50 & 22 & 12 \\
Juliusruh & 54.6 & 13.37 & 40 & 12 & 14 \\
Kühlungsborn & 54.1 & 11.77 & 91 & 22 & 17 \\
Katlenburg-Lindau & 51.7 & 10.12 & 145 & -14 & 15 \\
Collm & 51.3 & 13.00 & 234 & -14 & 16 \\
Pic du Midi & 42.9 & 0.14 & 2900 & 35 & 15 \\
Calar Alto & 37.2 & -2.55 & 2100 & 35 & 15 \\
\hline
\end{tabular}

The Bonn University RMR lidar uses density tuned etalons to perform NLC observations during daylight (Blum and Fricke, 2005). During the ECOMA campaign the system was operated with a vertical resolution of $150 \mathrm{~m}$ and a temporal resolution of about four minutes.

The IAP RMR lidar uses a vertical resolution of $200 \mathrm{~m}$ and a temporal resolution of $2.5 \mathrm{~min}$ for NLC retrievals (Gerding et al., 2007). Due to darkness during the NLC observations at this mid-latitude site, no etalon is used.

\subsection{Radars}

Mesospheric wind data are provided by the SKiYMET meteor radars operated at ALOMAR and Juliusruh. Both are all-sky systems which use crossed Yagi antennas for transmission to ensure a nearly uniform azimuthal sensitivity to meteor echoes. The echoes are received by a 5-antenna interferometer, resulting in a range accuracy of $2 \mathrm{~km}$ and an angular accuracy of better than $2^{\circ}$ in meteor location. Meteor observations have been performed at a frequency of about $32 \mathrm{MHz}$ with a pulse repetition frequency of $2144 \mathrm{~Hz}$, a pulse width of $13 \mu$ s (Gaussian shape) and a peak power of $12 \mathrm{~kW}$ (Singer et al., 2004).

\subsection{NLC Camera Network}

The Leibniz-Institute of Atmospheric Physics (IAP) has developed an automated camera system consisting of a highresolution digital camera (7 Megapixels) and a computer to control the camera. During summer 2007 seven cameras were in operation spanning a broad range of latitudes, namely from $37^{\circ} \mathrm{N}$ to $63^{\circ} \mathrm{N}$ (see Table 1 ). For the automated observation of the sky in the twilight period a control software was developed which allows the cameras to cover the huge dynamic range of the sky lights. The camera system calculates the exposure settings and the frame rate automatically from the solar elevation. Throughout the twilight period the cameras work continuously and deliver about two to three pictures per minute. The cameras at latitudes between $51^{\circ} \mathrm{N}$ and $63^{\circ} \mathrm{N}$ look towards the north (or
PMC occurrence frequency [1]

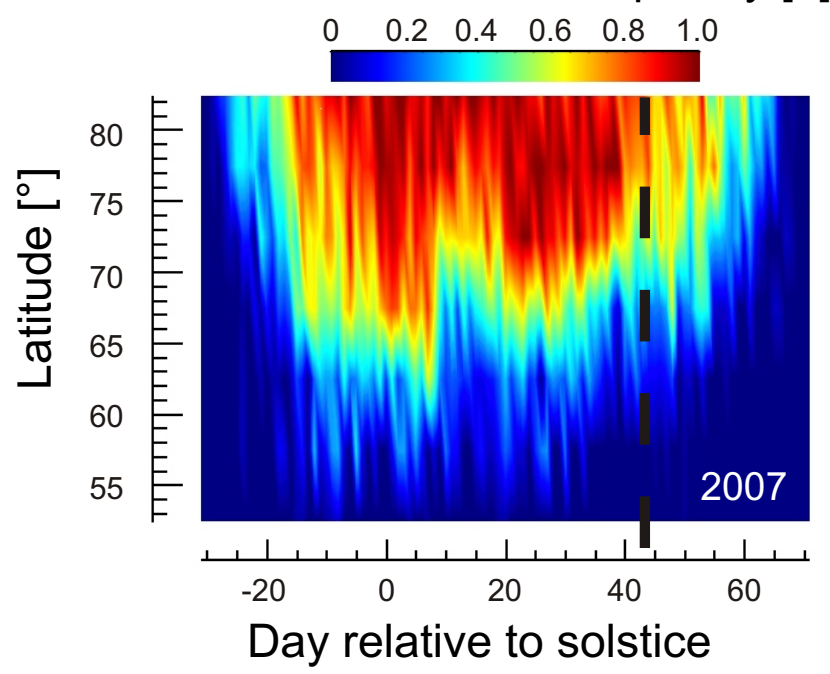

Fig. 1. Daily mean NLC occurrence frequency from middle to high latitudes during summer 2007 as observed by SCIAMACHY on Envisat. 3/4 August 2007 is marked by a black line.

towards the lidar stations) as their FOV is large enough to observe sunset and sunrise. The lower latitude cameras at Pic du Midi $\left(43^{\circ} \mathrm{N}\right)$, and Calar Alto $\left(37^{\circ} \mathrm{N}\right)$ look only towards the sunrise. The pictures are sent via Internet to the IAP on a near real-time basis and are stored into archives. During the NLC season the compressed data volume is about 3.5 GByte/day. For the interpretation of the images acquired by the cameras we map the pictures to a satellite view (Pautet and Moreels, 2002). For an accurate projection of the cloud the pointing of the camera needs to be known precisely. The viewing geometry is calibrated using stars visible in the images. This alignment was performed for several pictures during the ECOMA/MASS campaign. For the projection the corresponding azimuth and elevation of each point is calculated. Knowing the location of the observation site we use Eq. (4) and the following ones from Garcia et al. (1997). If the elevation of the point is lower than $13^{\circ}$, we correct it for the atmospheric refraction. Finally, the position of the point is obtained in the NLC picture using Eqs. (1) and (2) from Dalin et al. (2004).

\section{Observations}

The ECOMA/MASS sounding rocket campaign was conducted during the first weeks in August 2007. This time of the season is optimal for ground based observations by camera or lidar due to the low solar elevation. Indeed the first observation of a NLC by lidar was performed on 5/6 August 1989 from Andøya (Hansen et al., 1989). During the campaign period the occurrence frequency (OF) of noctilucent clouds is already reduced by $20 \%$ to $40 \%$ of the 

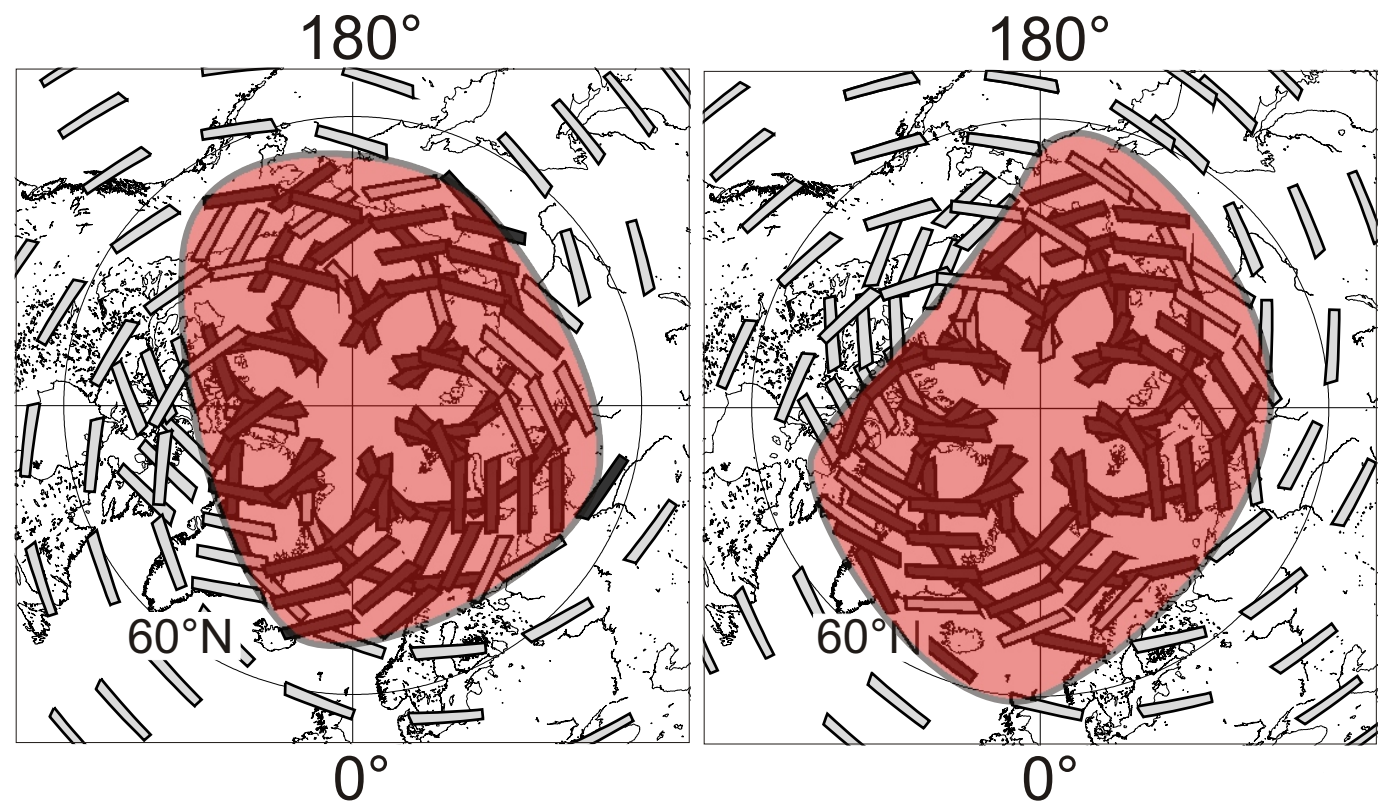

Fig. 2. PMC detection by SCIAMACHY on 3 August (left) and 4 August (right) 2007. Areas where PMC are observed are marked with dark boxes while confirmed absence of PMC is marked with pale boxes. The colored region depicts the PMC area.
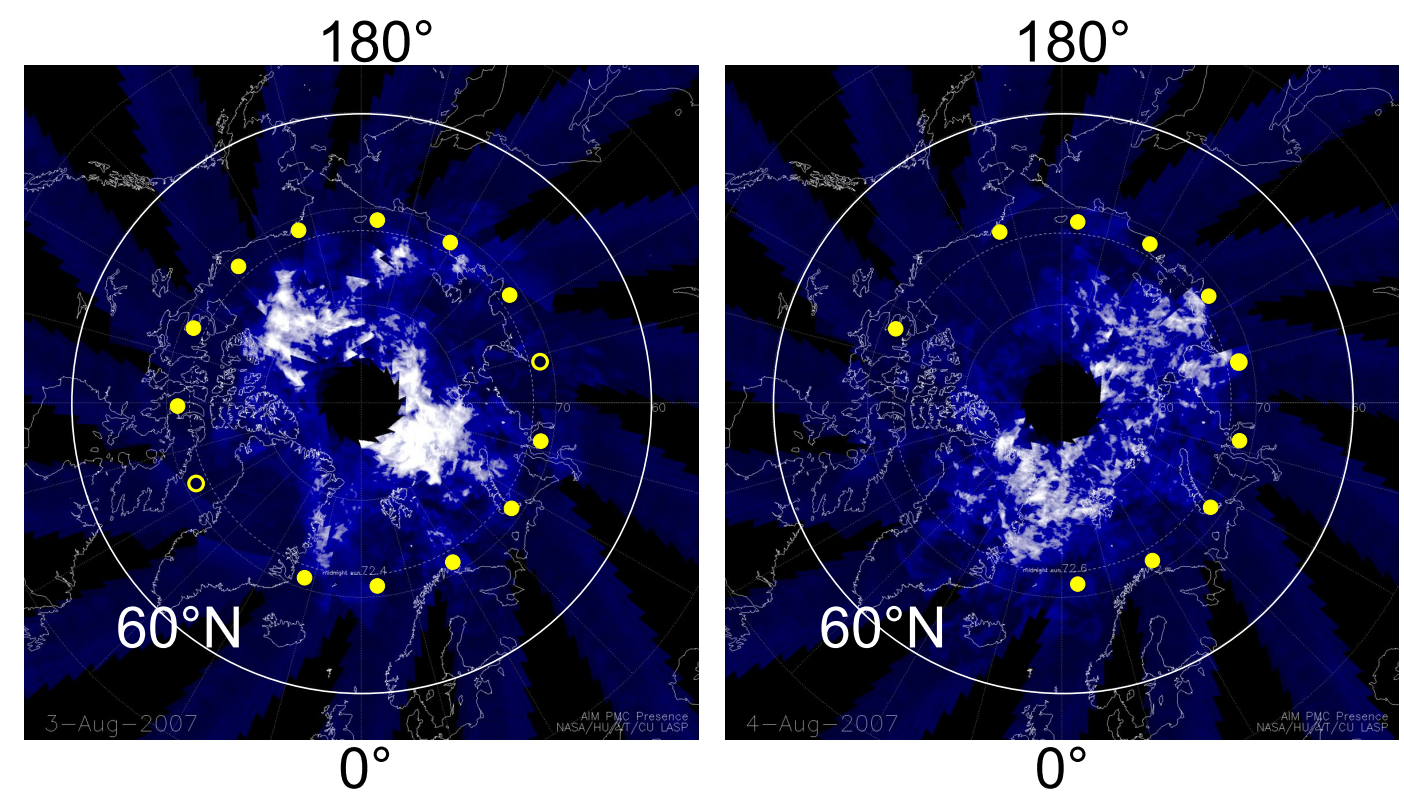

Fig. 3. A detailed view of PMC in the Northern Hemisphere on August 3 (left) and 4 August (right) 2007 by the CIPS experiment on AIM. The blue area is covered by the CIPS cameras with a resolution of $5 \times 5 \mathrm{~km}$ per pixel. The white regions are PMC measured by CIPS. Yellow circles mark measurements performed by the SOFIE instruments (see Fig. 4). Filled yellow circles indicate the detection of PMC by SOFIE.

peak occurrence reached about 20 days after solstice (Fiedler et al., 2009). As the results by Fiedler et al. (2009) are based on a combined dataset from several years of NLC measurements we show in Fig. 1 the daily averaged OF of the year 2007 as observed by SCIAMACHY (Robert et al., 2009). It is interesting to note that during this year the OF was decreasing slowly at the end of the season. Even in the mid- dle of the season from day 10 to 20 after solstice the OF at $70^{\circ} \mathrm{N}$ was comparable to the $\mathrm{OF}$ during the campaign period which could be an indication for long-period oscillations (Espy and Witt, 1996; DeLand et al., 2003). The summer 2007 showed also a rather long season with large day to day fluctuations due to planetary scale waves (c.f. Merkel et al., 2008; von Savigny et al., 2007). In detail, we observe 


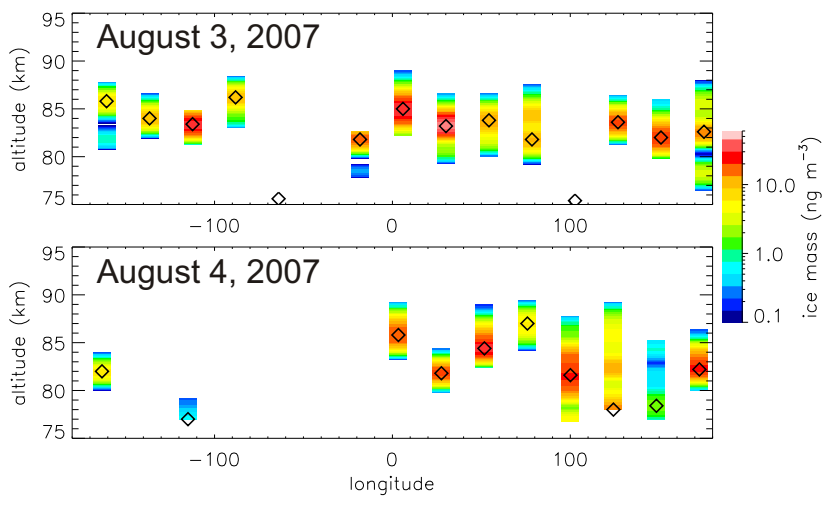

Fig. 4. Ice mass as observed by SOFIE on AIM on 3 August (upper) and 4 August (lower) 2007. Diamonds indicate the peak altitude of the PMC extinction. Color bars indicate the ice mass if a PMC could be identified at the tangent point. PMC detections below $80 \mathrm{~km}$ are very likely caused by near or far field PMC (Hervig et al., 2009). Confirmed absence of PMC is indicated by diamonds at $75 \mathrm{~km}$ altitude.

a strong 5-day wave activity in PMC occurrence at the end of the 2007 PMC season (not shown here), in contrast to the 2005 season, where the most pronounced 5-day wave activity occurred during the beginning of the season (days -10 to 5 relative to solstice) (von Savigny et al., 2007). Beginning around 2 August 2007 a clear 5-day wave signature is present in the NLC occurrence frequency and appears to be superimposed to other planetary wave features.

\subsection{Planetary scales}

Detailed analysis of the PMC detections in Fig. 2 shows a wave 2 structure with changing phase from 3 to 4 August. In Fig. 3 we show a similar picture but observed by the high resolution CIPS cameras on AIM. The pictures were downloaded from the webpage and enhanced with a nonlinear gamma correction of gamma $=3, \min =64, \max =200$ to enhance low intensity cloud structures. Using the CIPS images we observe the wave 2 structure more clearly, however in detail they show a much more structured PMC occurrence. For example on 3 August a spiral arm like structure (at about $180^{\circ}$ E) extends from the polar PMC field further south. Such a feature is frequently observed in the stratosphere and called streamer. Both SCIAMACHY and CIPS show PMC only poleward of $60^{\circ} \mathrm{N}$.

To investigate the vertical structure of the PMC on planetary scales we show in Fig. 4 the vertically resolved PMC ice mass from SOFIE measurements. The measurements were performed on 3 August at $71.2^{\circ} \mathrm{N}$ and on 4 August on $71.4^{\circ} \mathrm{N}$. We notice a variation of the NLC altitude with longitude from 82 to $87 \mathrm{~km}$. PMC detections with peak altitudes below $80 \mathrm{~km}$ are probably caused by near or far field PMC (Hervig et al., 2009). Some observations (e.g. $170^{\circ} \mathrm{E}$ on 3 August) show a double layer structure where one layer

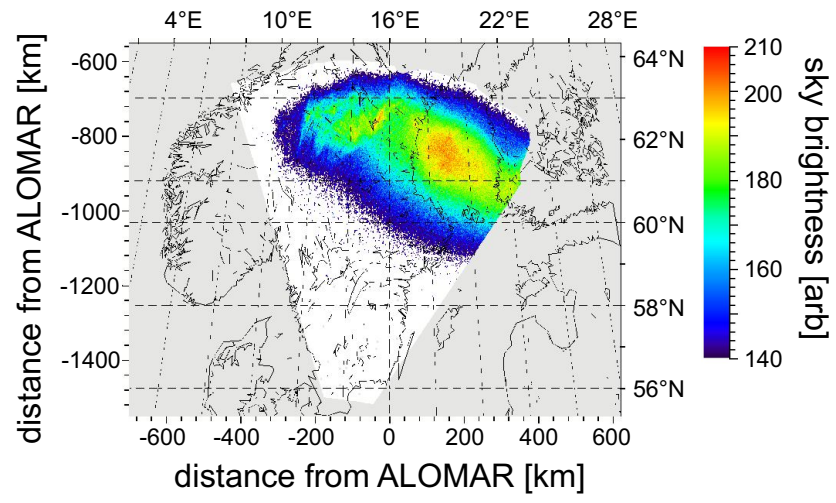

Fig. 5. Sky brightness observed from Juliusruh on 4 August, 01:35 UT in arbitrary units. The brightness was mapped assuming an scattering layer at $82.5 \mathrm{~km}$ altitude. The white cone marks the field of view of the camera. The sky brightness can be attributed directly to a NLC as the sun is $14^{\circ}$ below the horizon.

is below $80 \mathrm{~km}$. This is probably caused by two horizontally separated cloud fields, one of them at the tangent point and one in the near or the far field. Combining the results we conclude that on 3/4 August an intense planetary scale wave activity modulated the PMC field.

We now present surprising observations from the camera and lidar at lower latitudes. On 3/4 August a NLC was also observed by our cameras in Kühlungsborn and Juliusruh. From Kühlungsborn a cloud was visible during sunset from 20:48 to 21:44 UT and during sunrise on 4 August 2008 from 00:45 to 02:00 UT. From Juliusruh we observed a NLC from 20:48 to 22:20 UT and 00:30 to 02:14 UT. In Fig. 5 we show one projection of the cloud assuming an altitude of the cloud layer of $82.5 \mathrm{~km}$ as observed by the lidars (see below). Due to the low solar elevation of about $-14^{\circ}$ the sky brightness is caused by the NLC and only a negligible contribution comes from Rayleigh scattering on molecules. In fact the original pictures show the wave structures typically seen in NLC. The pictures indicate that the cloud extended southward to at least $59^{\circ} \mathrm{N}$. Due to the low solar elevation the cloud was not illuminated, or too weak to be seen further south.

The brightest parts of the clouds were located above middle Sweden, at about $62^{\circ} \mathrm{N}$. Neither of our cameras at $51^{\circ} \mathrm{N}$ nor our camera at $37^{\circ} \mathrm{N}$ observed a NLC that night despite of clear tropospheric conditions. Due to the low solar elevation around local midnight at Kühlungsborn and Juliusruh, the cloud was not observed by the cameras between the evening and morning twilight. Nevertheless, using the lidar at Kühlungsborn we observed that a noctilucent cloud was present even further south of $59^{\circ} \mathrm{N}$, at least to the latitude of the lidar $\left(54^{\circ} \mathrm{N}\right)$. Figure 6 shows the backscatter coefficient of the NLC above the IAP. During the lidar observation we have simultaneous wind observations from the meteor radar at Juliusruh. The distance between Juliusruh and Kühlungsborn $(\sim 120 \mathrm{~km})$ is small compared to the 


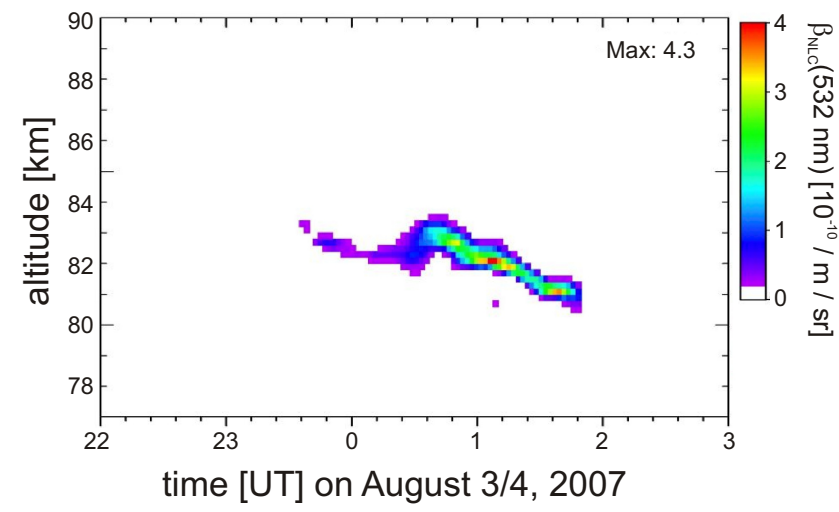

Fig. 6. Temporal evolution of the noctilucent cloud above the IAP $\left(54^{\circ} \mathrm{N}\right)$ on $3 / 4$ August 2007 as measured by the RMR-lidar. The peak backscattering of $4.3 \times 10^{-10} \mathrm{~m}^{-1} \mathrm{sr}^{-1}$ was reached about 01:00 UT.

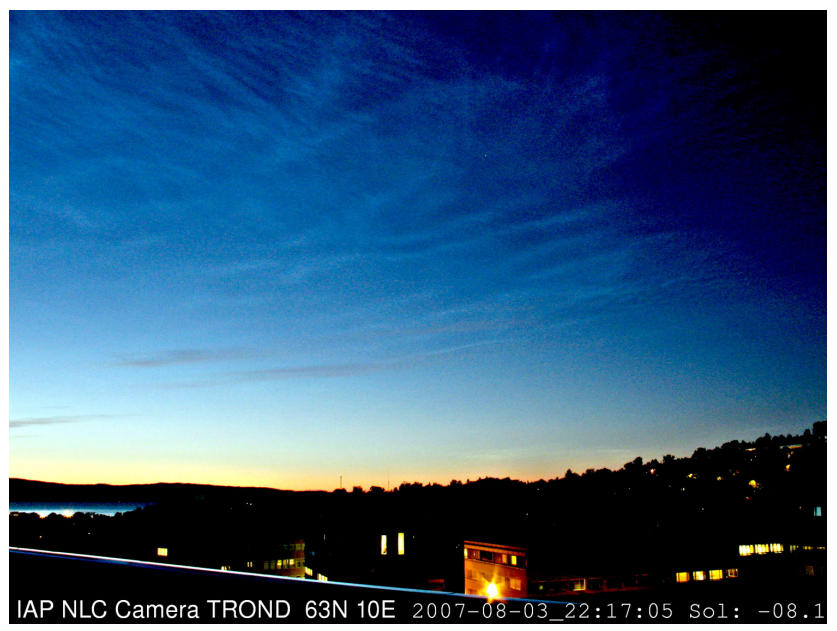

Fig. 7. Noctilucent cloud observed by camera from Trondheim on 3 August 2007 22:17 UT during the AIM overpass. To emphasize the cloud structures the raw image was processed by a 50 point unsharpmask of weight 0.8 .

sounding volume of the radar, so these observations are representative for the clouds observed above the IAP. The measurements show a downward progression of the NLC layer from about $83 \mathrm{~km}$ to about $81 \mathrm{~km}$. The peak brightness is $2-4 \times 10^{-10} \mathrm{~m}^{-1} \mathrm{sr}^{-1}$ which corresponds to a medium to strong NLC at Kühlungsborn. Only $18 \%$ of all NLC detections at this location show a brightness larger than $4 \times 10^{-10} \mathrm{~m}^{-1} \mathrm{sr}^{-1}$. To understand the origin of the NLC the wind has been analyzed: between 22:30 and 01:30 UT the meteor radar showed a strong southward directed meridional component of about $-60 \mathrm{~m} / \mathrm{s}$ at an altitude of about $82 \mathrm{~km}$. At $85 \mathrm{~km}$ altitude we observed also a strong southward directed wind that decreased from $-50 \mathrm{~m} / \mathrm{s}$ to $-20 \mathrm{~m} / \mathrm{s}$ between 22:30 and 00:30 UT. At 01:30 the direction changed to a northward directed wind with a meridional component of

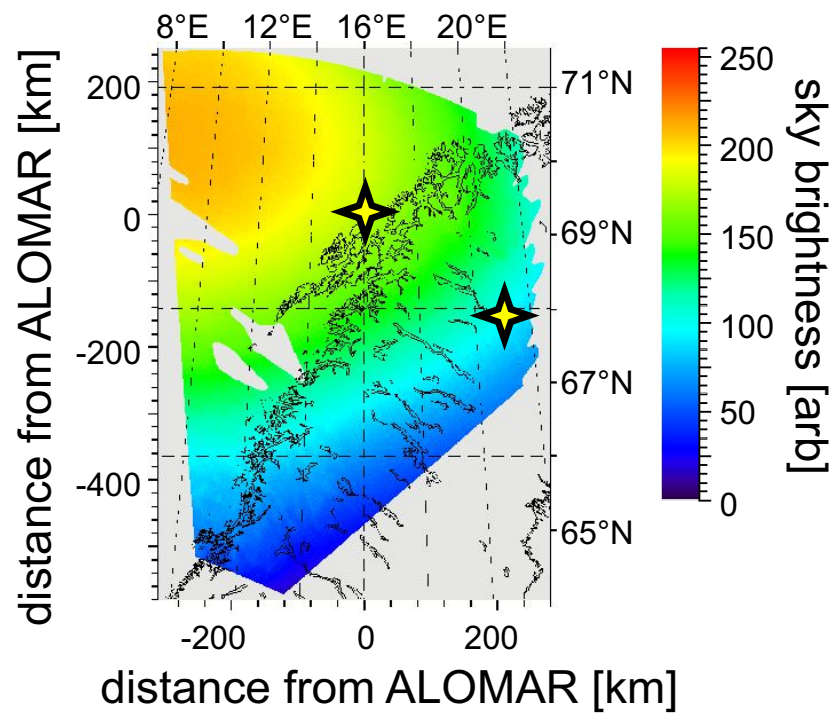

Fig. 8. Sky brightness observed from Trondheim on 3 August 2007 22:17 UT mapped to a scattering layer at $82.5 \mathrm{~km}$ altitude (cf. Fig. 7). The locations of ALOMAR and the Esrange are marked by black symbols. The colored area indicates the field of view of the camera, areas outside the field of view or contaminated by tropospheric clouds are grayed out. The picture is cut off at about $23^{\circ} \mathrm{E}$ due to the trees in the original picture. A large amount of the sky brightness is caused by Rayleigh scattering on molecules in the atmosphere. NLC structures are barely visible as the sun is only $8^{\circ}$ below the horizon.

$6 \mathrm{~m} / \mathrm{s}$. At both altitudes the westward directed zonal component increased from about $-25 \mathrm{~m} / \mathrm{s}$ to $-65 \mathrm{~m} / \mathrm{s}$. These southward directed strong winds are probably caused by planetary or large scale gravity waves that enabled the propagation of the NLC to lower latitudes.

\subsection{Local scales}

In Fig. 7 we show a picture of NLC observed from Trondheim during the overpass of AIM (22:17 UT) on 3 August. Especially in the upper part of the picture we recognize a bright NLC.

\subsubsection{Comparison of different observation methods}

We now compare camera results from Trondheim in detail to lidar and CIPS. We start with the picture shown in Fig. 7 observed during the AIM overpass. The original picture shows distinct NLC structures in the upper half of the picture and faint structures just above the trees in the middle-right part of the picture.

Figure 8 shows the sky brightness mapped to an altitude of $82.5 \mathrm{~km}$. Comparing the projected picture to the original we observe that it is nearly impossible to realize the NLC structures visible in the raw picture (Fig. 7) which should appear around $65^{\circ} \mathrm{N}$. This is caused by the large contribution of 


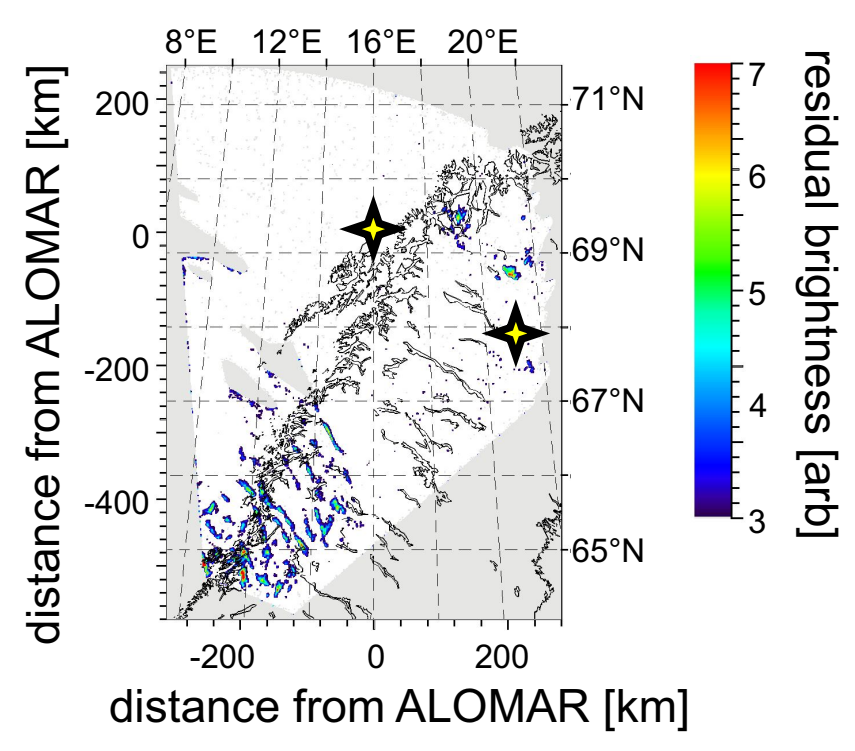

Fig. 9. Residual sky brightness observed from Trondheim on $3 \mathrm{Au}-$ gust 2007 22:17 UT with enhanced NLC structures. A detailed description of the structure enhancement is given in the text. ALOMAR and the Esrange are marked by black symbols.

Rayleigh scattering to the sky brightness although the sun is about $8^{\circ}$ below the horizon. We have developed a method for background removal and NLC structure enhancement. The method enhances local intensity increases due to structures in NLC and suppresses larger scale intensity variations throughout the picture. First we estimate a mean background using a $81 \times 81$ pixel smoothing which corresponds to about $32 \times 32 \mathrm{~km}$ at the NLC layer. This background is subtracted from the original picture to obtain residual fluctuations. Positive fluctuations are then removed from the original picture and the background estimation is repeated. This method results in a background nearly free of NLC contributions. The background estimation is then iterated with $41 \times 41,21 \times 21$ and $11 \times 11$ pixel. Finally the background is subtracted from the original picture to yield the residual sky brightness, which we will call brightness of the NLC. The method enhances cloud structures that are smaller than $4 \times 4 \mathrm{~km}$ around $68^{\circ} \mathrm{N}$ or $10 \times 10 \mathrm{~km}$ for latitudes above $70^{\circ} \mathrm{N}$.

Figure 9 shows the result of the background removal. The method enhances the NLC structures and we find a NLC display from about $64^{\circ}$ to $67^{\circ} \mathrm{N}$ and a fainter and more localized cloud patch around $69.5^{\circ} \mathrm{N}, 22^{\circ} \mathrm{E}$, about $100 \mathrm{~km}$ north of the Esrange. We could not identify a corresponding PMC display for the NLC between $64^{\circ}$ and $67^{\circ} \mathrm{N}$ in the CIPS images. Nor did we find at that time and further south a NLC display in the images from Kühlungsborn or Juliusruh. For the two ground based cameras this is clearly caused by the missing illumination, as the solar elevation is already below $-16^{\circ}$. Investigating the differences between the observations of the camera in Trondheim and CIPS we have to take the different wavelengths of the two instruments into account.

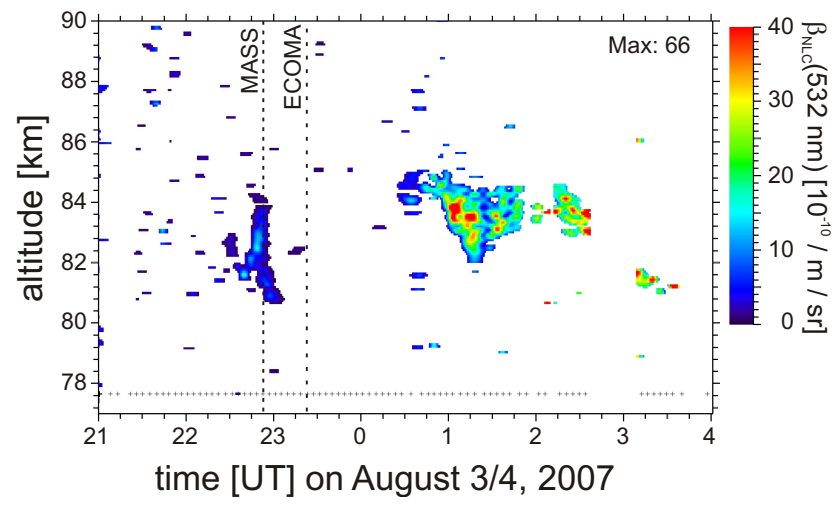

Fig. 10. Temporal evolution of the noctilucent cloud above the Esrange on 3/4 August 2007 as measured by the University of Bonn lidar.

The ground-based camera uses visible light scattered from the clouds while CIPS observes the clouds at a much shorter wavelength of only $265 \mathrm{~nm}$. Due to the absorption of UV light in the ozone layer the clouds between $64^{\circ} \mathrm{N}$ and $67^{\circ} \mathrm{N}$ are probably not illuminated by the low Sun at the wavelength observed by CIPS. The ozone layer will appear like an increase in the earth radius of about $35 \mathrm{~km}$. This will move the earth's shadow at the clouds about two degrees northward, compatible to our observations.

When comparing the projected images to lidar measurements it is essential to know the accuracy of the projection since the lidar sounding volume is rather small. Taking advection during the measurement into account Baumgarten and Fiedler (2008) calculated an horizontal extent of the sampling volume of about $40 \mathrm{~km} \times 200 \mathrm{~m}$ for a $14 \mathrm{~min}$ sounding. Taking the time resolution of the lidars during the ECOMA/MASS campaign into account we find an horizontal extent of $11 \mathrm{~km} \times 250 \mathrm{~m}$ for the Esrange Lidar and $1.2 \mathrm{~km} \times 200 \mathrm{~m}$ for the ALOMAR RMR lidar.

The horizontal resolution of the projected images at the NLC altitude is on average $400 \mathrm{~m}$ but decreases to about $1 \mathrm{~km}$ at $70^{\circ} \mathrm{N}$. Essential for a detailed comparison is the knowledge of the pointing of the camera. We have calibrated the pointing and the field of view of the camera using star positions which were photographed simultaneously with the noctilucent clouds. The quality of this method was investigated by repeating the calibration several times during the night. It turns out that the pointing is known with an accuracy better than $0.1^{\circ}$. This pointing uncertainty corresponds to a projection error of about $7 \mathrm{~km}$ above ALOMAR. Another uncertainty in the projection comes from the altitude of the layer. An altitude uncertainty of $1 \mathrm{~km}$ corresponds to an horizontal error of the projection of about $6 \mathrm{~km}$.

To compare the image taken during the AIM overpass with the lidar results we first turn to the observations by the lidar at the Esrange since there were no observations from ALOMAR at that time. The lidar observations during the night 

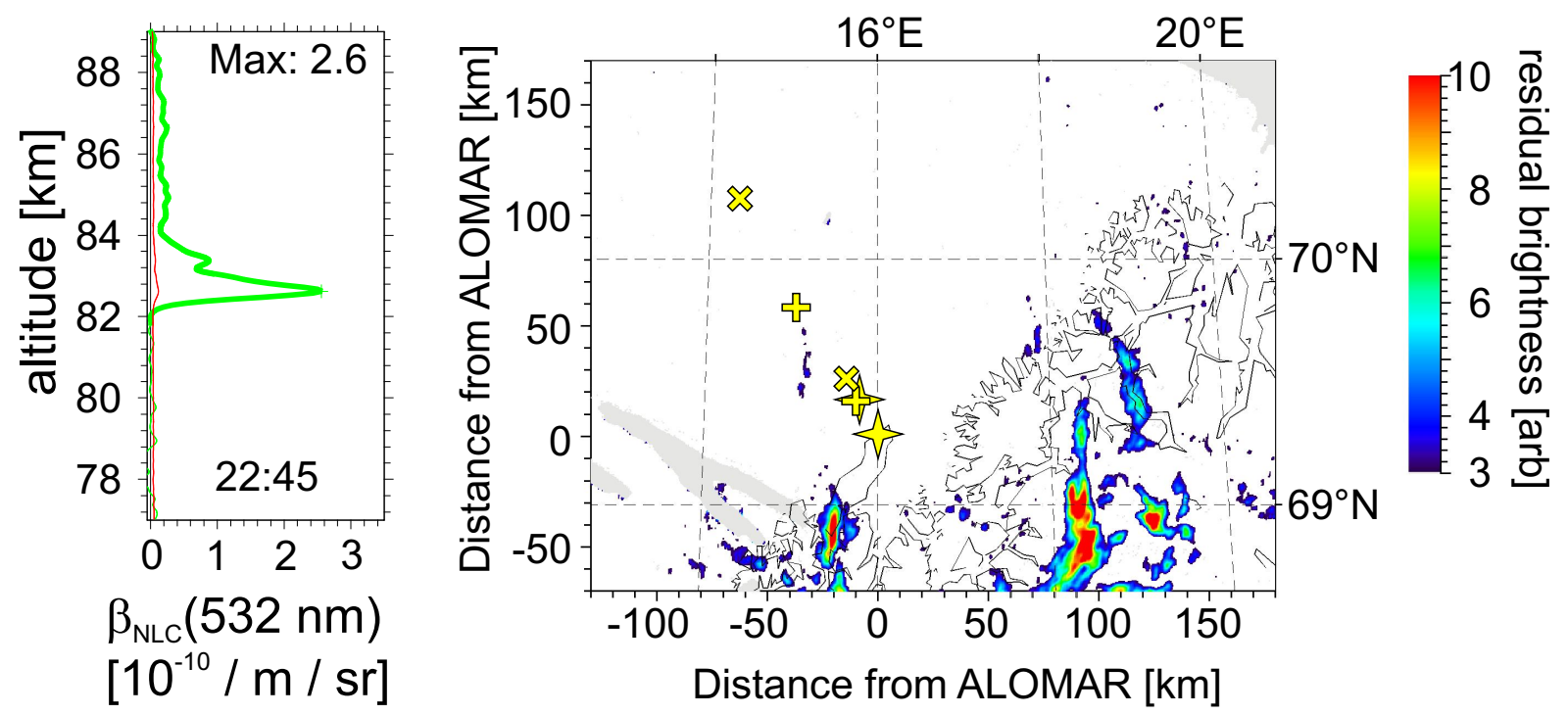

Fig. 11. Backscatter coefficient as measured by the ALOMAR RMR lidar on 3 August 2007 22:45 UT with the North-West telescope (left) and simultaneous residual sky brightness (right) similar to Fig. 9. Areas in the image where tropospheric clouds north of Trondheim have disturbed the view towards ALOMAR were masked out and appear gray in the projected residual brightness. Stars in the map mark the lidar sounding volumes, pluses mark the ECOMA measurements on up and downleg and x-symbols mark the MASS measurements.

are shown in Fig. 10. A weak to medium NLC was observed around 22:50 and a strong NLC was observed in the morning hours. During the AIM overpass at 22:17 UT both the lidar and the camera agree and show no detectable NLC above the Esrange. A more detailed comparison to the Esrange lidar observations is not possible since the camera field of view was decreased later to achieve a better resolution above ALOMAR during the countdown for the rockets.

We now compare the camera observations to the RMRlidar observations above and north-west of ALOMAR. During the countdown the pointing of one of the RMR-lidar systems was towards the north-west to measure in a common volume with the ECOMA rocket. The North-West telescope (NWT) was pointing to $333^{\circ}$ Azimuth, and $13.5^{\circ}$ zenith distance while the South-East telescope (SET) was measuring vertically. The separation of the tilted lidar beam and the ECOMA trajectory was less than $2.0 \mathrm{~km}$ in the altitude range between $80 \mathrm{~km}$ and $90 \mathrm{~km}$. It was possible to perform lidar measurements through some holes in the tropospheric clouds shortly before the MASS launch and between the MASS and ECOMA sounding rocket flights. We have selected about $4.5 \mathrm{~min}$ of lidar measurements centered at 22:45 UT to compare in detail with the camera observations. In Figure 11 we show the comparison of the NWT to the camera results. At that time the SET was operated with polarizer and can not be used for direct NLC comparisons. The peak backscatter coefficient observed by the NWT was only $\beta=(2.6 \pm 0.1) \times 10^{-10} \mathrm{~m}^{-1} \mathrm{sr}^{-1}$ which corresponds to a faint NLC for this location (Fiedler et al., 2009). To improve the signal to noise ratio of the NLC camera in Trondheim the results shown are smoothed by a $7 \times 7$ point running mean to suppress high frequency fluctuations that are partly induced by the data compression algorithm. Due to the NLC structure enhancement method it could happen that a homogeneous NLC layer is removed from the residual intensity plots. We therefore investigated the structure of the NLC layer above ALOMAR using the two beams of the lidar. Figure 12 shows 5 min of lidar measurements. Around 22:59 UT we observe a different structure of the clouds above the station (lower row) and towards the north-west. The separation of the two beams at the cloud altitude is $\sim 20 \mathrm{~km}$. There is an obvious difference between the two observations. While the NWT observes two separated cloud layers the SET observes only one layer during the simultaneous observations. During the following minutes the cloud observed by the SET varies in altitude by about $200 \mathrm{~m}$. At 23:03:43 UT about 5 min after the observation of the upper cloud layer in the NWT we observe an upper layer also in the SET. In summary the lidar observes small scale structures in the NLC. We conclude that for the special observation geometry of our camera (about $700 \mathrm{~km}$ south of ALOMAR) and the solar elevation of about $-9^{\circ}$ a NLC with a backscatter coefficient of less than $\beta=3 \times 10^{-10} \mathrm{~m}^{-1} \mathrm{sr}^{-1}$ can not be detected by the camera. We like to emphasize that the distance from the camera to ALOMAR is not the limiting factor, and also that there are small scale structures present in the NLC above ALOMAR, as observed by the lidar. These structures should be enhanced by our method for calculating the residual sky brightness. In Fig. 11 we observe clear NLC structures about $100 \mathrm{~km}$ east of ALOMAR which indicates that the camera indeed shows NLC structures (if present) as far north as ALOMAR. 


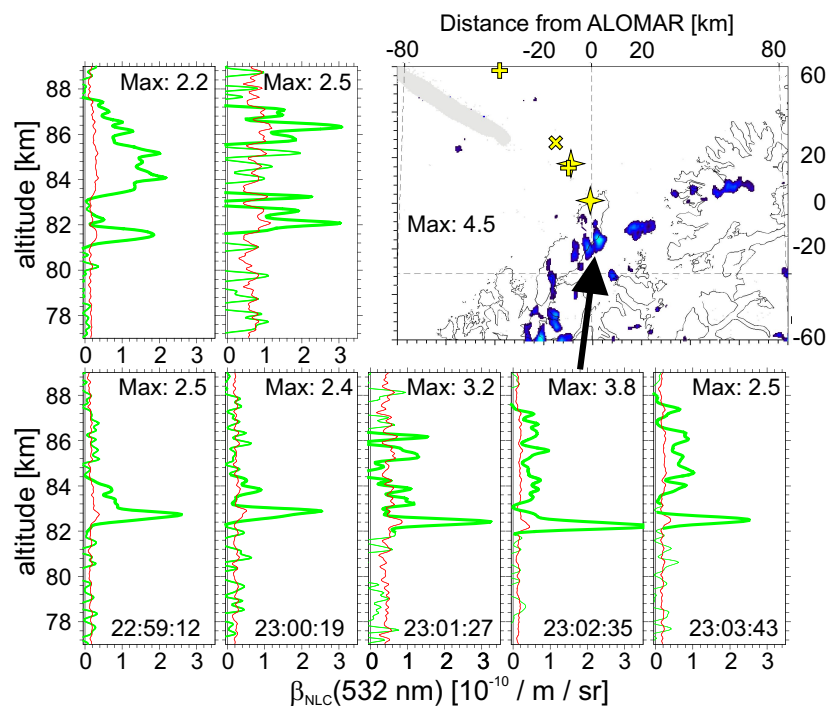

Fig. 12. Temporal evolution of the NLC observed by ALOMAR RMR-lidar from 22:59 to 23:04 UT. The upper row shows the NWT observations towards the North-West. The lower row shows measurements by the SET above ALOMAR. Tropospheric clouds blocked the NWT beam after 23:00. In the upper row we also show a map of the faint NLC as observed by the camera at 23:02:37 UT. Stars in the map mark the lidar sounding volumes, pluses mark the ECOMA measurements on up and downleg and $\mathrm{x}$-symbols mark the MASS measurements

The detailed comparison of the detection threshold of the ground based cameras is of importance when comparing the camera observations to the rocket results. While for example the original NLC picture as taken from Trondheim suggest the presence of a strong NLC during the ECOMA launch (Fig. 13), the projection of the residual sky brightness shows that there was indeed a strong NLC, but about $100 \mathrm{~km}$ south of ALOMAR. In the area where the ECOMA or MASS payload measured properties of the cloud layer we found only weak NLC (by lidar) which are below the detection threshold of the camera. A detailed investigation of the rocket results and comparisons to the lidar measurements are found in Robertson et al. (2009); Megner et al. (2009); Rapp et al. (2009). In the previous sections we combined several observation methods to deduce the morphology on global scales and to investigate the sensitivity of our camera systems. We now study the morphology of the NLC on local scales and its temporal evolution.

\subsubsection{Temporal evolution on local scales}

We show in Fig. 14 snapshots of the NLC structure between 22:53 UT and 23:43 UT. The upper (lower) left panel shows the NLC structure at the time when the MASS (ECOMA) payloads penetrated the NLC layer on upleg. When investigating the NLC development in detail we observe that the cloud intensifies with time. Already around 23:23 UT a

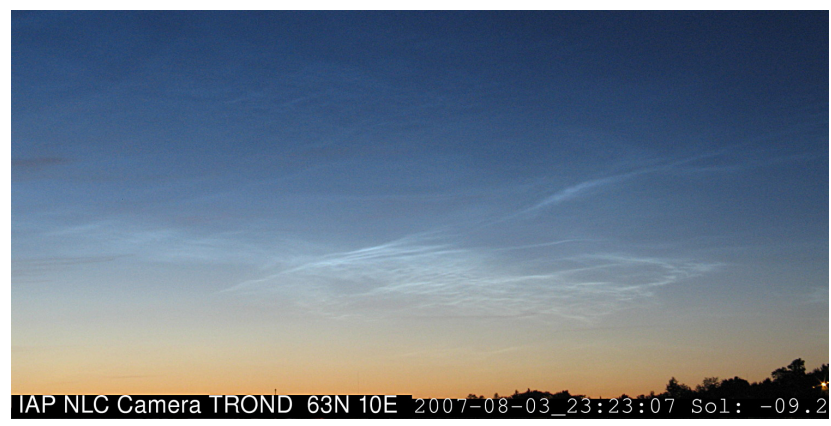

Fig. 13. Close up of the noctilucent cloud observed from Trondheim on 3 August 2007 23:23 UT during the ECOMA flight. The time is given in the photo.

nearly $250 \mathrm{~km}$ long but only $10 \mathrm{~km}$ wide rogue wave develops. The narrow wave crest runs from North-North-West to South-South-East. The amplitude of the wave increases in a roughly $100 \mathrm{~km}$ long section till about 23:35 UT and remains at a residual brightness of about 40 . Initially we observe an extended wave-field towards the North-East of the crest. Throughout the observation the extent perpendicular to the wave-crest decreases.

To investigate the cloud development in more detail we study the wind at the altitude of the NLC. Using the wind information we can take the advection of the particles into account. In Fig. 15 we show the wind above ALOMAR on $3 / 4$ August. It is remarkable that we observe a strong $12 \mathrm{~h}$ variation of the wind with an amplitude of about $30 \mathrm{~m} / \mathrm{s}$ at $82 \mathrm{~km}$ altitude. A similar strong tide was observed at Juliusruh (not shown here). This amplitude is significantly larger than the mean values in early August (Riggin et al., 2003). Throughout the NLC presence we observe prevailing wind from North-East of $53 \mathrm{~m} / \mathrm{s}$. We have extracted the brightness from the projected pictures along the wind vector going through a point $140 \mathrm{~km}$ south of ALOMAR (cf. Fig. 14). The results are shown in Fig. 16 for the different measurements from 22:40 UT to 00:06 UT. The separation between the measurements is roughly $30 \mathrm{~s}$. To separate the successive observations we added one brightness unit per measurement.

The trajectory of a passive tracer that would be transported by the background wind goes from the lower right to the upper left. We note that the intensity features of the NLC follow those of a passive tracer despite the fact that the intensity increases with time until it is suddenly reduced. The detailed investigation of the brightness features shows also an intensity modulation on scales of $10 \mathrm{~km}$ or less, however this is at the limit of the resolution of the algorithm needed for background removal and noise suppression. It is interesting to note that the rogue wave is closely correlated to the destruction of the NLC structure. As the NLC is transported southward the brightness increases until it reaches the rogue wave at $-70 \pm 10 \mathrm{~km}$ throughout the $1.5 \mathrm{~h}$ observation. Shortly after the peak brightness is reached the brightness falls below 


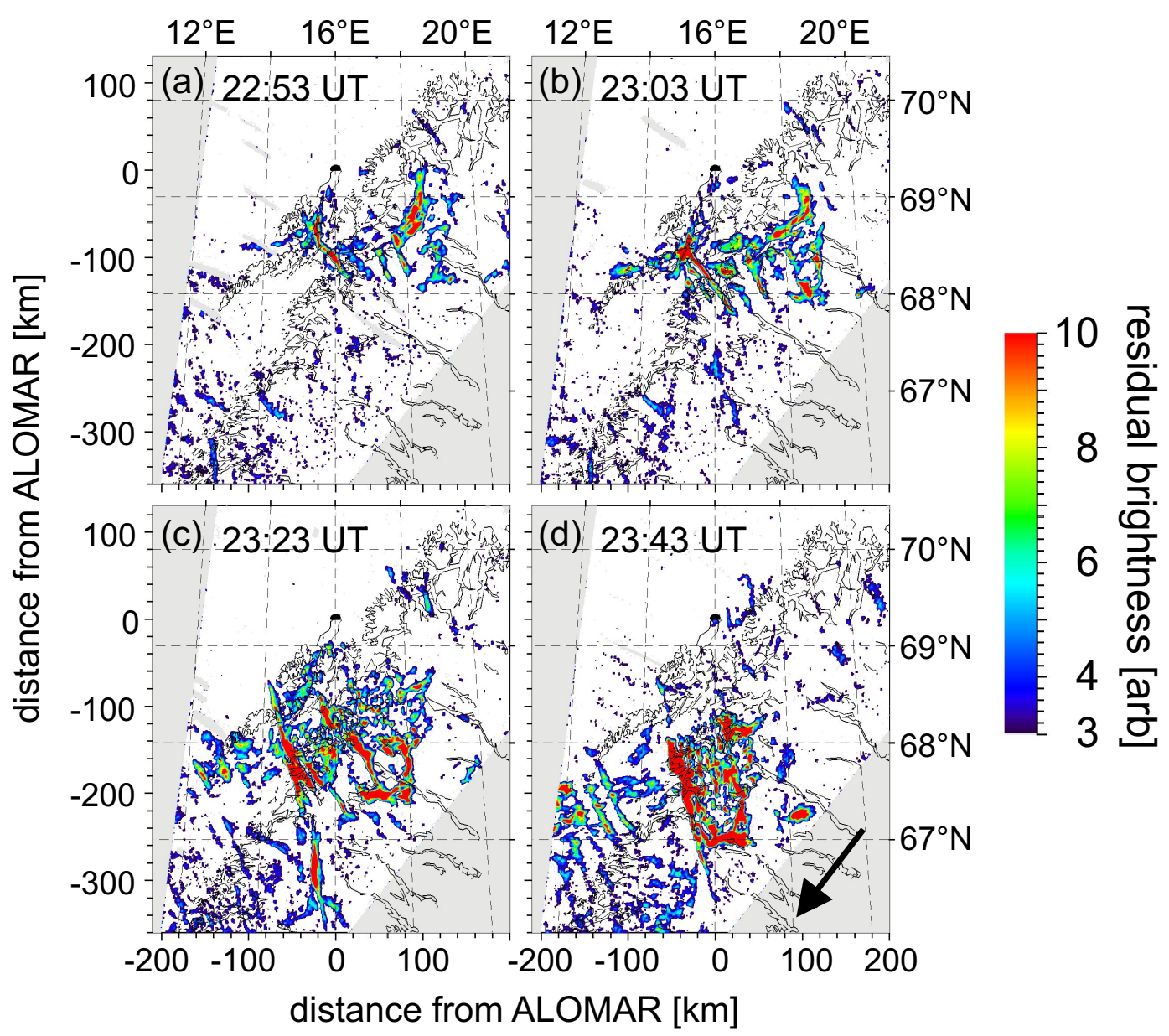

Fig. 14. Temporal evolution of the noctilucent cloud (a) 22:53 UT; (b) 23:03 UT; (c) 23:23 UT; (d) 23:43 UT. The same color scale as in Fig. 11 is used. The wind direction as measured by the SKiYMET radar at ALOMAR is indicated by an arrow.

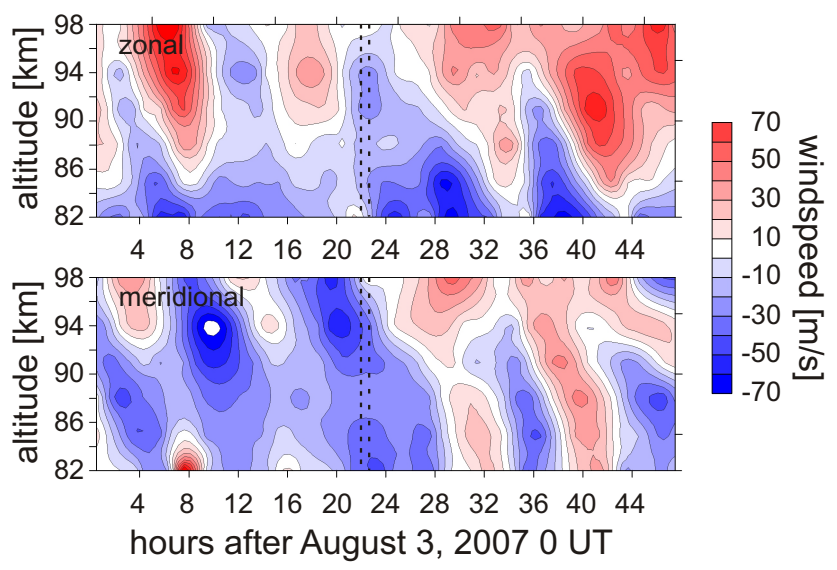

Fig. 15. Temporal evolution of the wind field above ALOMAR on 3/4 August 2007 as measured by the meteor radar. The time of the MASS and the ECOMA sounding rocket launches are marked by vertical lines. the detection limit within 5 to $10 \mathrm{~km}$. The sharpest gradients are observed around $-70 \mathrm{~km}$ and 22:50 UT. Here we find a peak brightness of about 42 . Using the comparison of the lidar sensitivity and the camera we come to the conclusion that this is a remarkably bright NLC. The estimated lidar backscatter coefficient is about $40-80 \times 10^{-10} \mathrm{~m}^{-1} \mathrm{sr}^{-1}$. The results are compatible with the lidar observations at the Esrange, where a strong NLC with a backscatter coefficient of $66 \times 10^{-10} \mathrm{~m}^{-1} \mathrm{sr}^{-1}$ was observed. The camera observations show that the brightness of the strong NLC decreases by a factor of 20-40 and the NLC becomes invisible within a horizontal distance of $5 \mathrm{~km}$. Following the movement of an air parcel we calculate that the brightness decreases within 80 to $120 \mathrm{~s}$.

A brightness reduction of a factor of 20-40 can be explained by a particle radius change of about $60 \%-80 \%$. Starting from the size of the particles in strong clouds of $50 \mathrm{~nm}$ we calculate a radius reduction of $30-40 \mathrm{~nm}$. We calculated the evaporation rates for background conditions at ALOMAR assuming water vapor mixing ratios of 2-10 ppm (Lübken, 
1999). Using the quotations in Hesstvedt (1961) we find that the temperature was $14-18 \mathrm{~K}$ above the frost point. So from the distance of the wave crest to the place where the NLC becomes invisible ( $\sim 5 \mathrm{~km}$ south-westward) we calculate a horizontal temperature gradient of $3 \mathrm{~K} / \mathrm{km}$ or more.

It is remarkable to note that the cloud intensity increases until the particles reach the rogue wave, the strongest brightness increase is observed shortly before the wave crest is reached. Furthermore it is astonishing that the rogue wave is localized within $10 \mathrm{~km}$ over a period of nearly $0.5 \mathrm{~h}$. Such a stationary pattern might be caused by gravity waves propagating against the wind with a phase speed equal to the windspeed. This interpretation is further supported by Fig. 14c and d. Here we observe wave structures also downwind of the rogue wave. These wave structures show that the smaller NLC particles downstream of the rogue wave have grown large enough to become visible again. The wavelengths visible are about $20 \mathrm{~km}$. In the NLC field to the North-East of the rogue wave even shorter scale wavelengths can be observed and are consistent with the results previously published by Witt (1962).

\section{Conclusions}

We have combined several passive and active remote sensing instruments to investigate the morphology of the NLC/PMC on $3 / 4$ August 2007 on global to local scales. In this manuscript we show for the first time simultaneous observations from lidar, satellite and cameras on different scales. A planetary wave 2 structure was observed from the satellite instruments with an even higher structured PMC display showing a streamer-like structure. Wind observations at ALOMAR and Juliusruh suggest that a strong $12 \mathrm{~h}$ tide induced a fast north-south transport. These strong winds, probably in combination with a cold phase of a planetary scale wave finally led to mid latitude NLC observations unusual late in the season. The NLC observed from Kühlungsborn is indeed a rather strong one, only $18 \%$ of the NLC above Kühlungsborn show a higher backscatter coefficient.

Lidar and camera observe highly structured NLC at ALOMAR: For example the lidar observed a different vertical structure within a distance of only $20 \mathrm{~km}$. The camera observes NLC structures with wavelengths of $20 \mathrm{~km}$ and less. By comparison to the lidar measurements we estimated the detection limit of the camera system to be about $\beta=4 \times 10^{-10} \mathrm{~m}^{-1} \mathrm{sr}^{-1}$. During the rocket launches the camera observed no NLC in the target area with $\beta>4 \times 10^{-10} \mathrm{~m}^{-1} \mathrm{sr}^{-1}$. The camera observations are compatible with the ECOMA rocket observations that estimated a

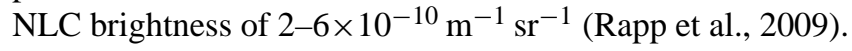
A highly structured and intense NLC was observed south east of ALOMAR during the MASS/ECOMA launches. A detailed investigation of the cloud structures along the transport direction shows that the NLC behaves like a slowly

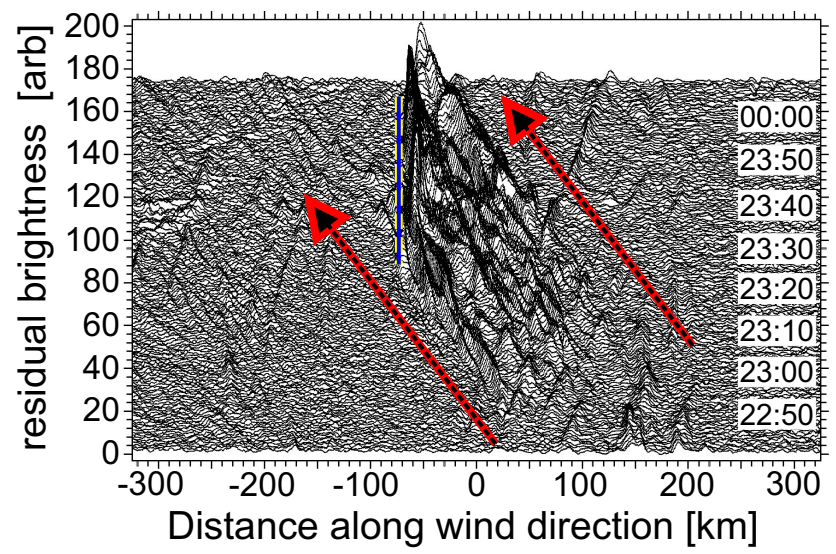

Fig. 16. Residual brightness along the direction of wind vector for different times between 22:40 UT and 01:00 UT. The brightness is increased by 1 for successive measurements. Positive distances are north-east of the origin. The brightness is smoothed by a $1.5 \mathrm{~km}$ running mean. Red arrows mark Lagrangeian transport. An intensity feature of a passive tracer would move along the red arrows. The bottom of the rogue wave is marked by a yellow-blue line.

reacting tracer, transported with the mean circulation. The NLC shows a remarkable stable, strong, and elongated rogue wave with a length of about $250 \mathrm{~km}$ and an extent along the wind direction of only $10 \mathrm{~km}$. The NLC brightness increases slowly until it reaches the rogue wave. At the wave crest the brightness is first intensified and then reduced by a factor of 20-40 in about $100 \mathrm{~s}$. Such a fast destruction can be explained by temperatures about $15 \mathrm{~K}$ above the frostpoint temperature. The rogue wave was rather localized and stationary probably caused by gravity waves traveling against the mean wind. These waves are indeed observed by the camera as the NLC particles grow sufficiently to be observed in the cold phase of the waves.

Acknowledgements. We gratefully acknowledge the support of the ALOMAR staff during the countdown periods. The project was supported by the Department of Physics of the Norwegian University of Science and Technology in Trondheim who supplied the infrastructure for the noctilucent cloud camera. We acknowledge the support of the University of Bonn lidar at the Esrange by several lidar operators from IRF, MISU and the Esrange. Special thank goes to Michael Priester for his effort on the IAP noctilucent cloud camera network. The analysis was supported by dedicated summer students. For this year the student was Dörte Petzsch. We received research funding from the European Community's 6th Framework Program under the project "ALOMAR eARI" (RITACT-2003-506208). SCIAMACHY is jointly funded by Germany, the Netherlands, and Belgium. The analysis of SCIAMACHY data was supported by the University of Bremen within the project ICAPS. The AIM mission is supported by NASA's Small Explorer's Office. The ECOMA project is sponsored by the German Space Center under DLR-grant 50OE0301.

Topical Editor C. Jacobi thanks E. Shettle and another anonymous referee for their help in evaluating this paper. 


\section{References}

Baumgarten, G. and Fiedler, J.: Vertical structure of particle properties and water content in noctilucent clouds, Geophys. Res. Lett., 35, L10811, doi:10.1029/2007GL033084, 2008.

Baumgarten, G., Lübken, F.-J., and Fricke, K. H.: First observation of one noctilucent cloud by a twin lidar in two different directions, Ann. Geophys., 20, 1863-1868, 2002, http://www.ann-geophys.net/20/1863/2002/.

Baumgarten, G., Fiedler, J., Lübken, F.-J., and von Cossart, G.: Particle properties and water content of noctilucent clouds and their interannual variation, J. Geophys. Res., 113, D06203, doi: 10.1029/2007JD008884, 2008.

Blum, U. and Fricke, K. H.: The Bonn University lidar at the Esrange: technical description and capabilities for atmospheric research, Ann. Geophys., 23, 1645-1658, 2005, http://www.ann-geophys.net/23/1645/2005/.

Dalin, P., Kirkwood, S., Moström, A., Stebel, K., Hoffmann, P., and Singer, W.: A case study of gravity waves in noctilucent clouds, Ann. Geophys., 22, 1875-1884, 2004, http://www.ann-geophys.net/22/1875/2004/.

Dalin, P., Pertsev, N., Zadorozhny, A., Connors, M., Schofield, I., Shelton, I., Zalcik, M., McEwan, T., McEachran, I., Frandsen, S., Hansen, O., Andersen, H., Sukhodoev, V., Perminov, V., and Romejko, V.: Ground-based observations of noctilucent clouds with a northern hemisphere network of automatic digital cameras, J. Atmos. Solar-Terr. Phys., 70, 1460-1472, doi: 10.1016/j.jastp.2008.04.018, available online, in press, 2009.

DeLand, M. T., Shettle, E. P., Thomas, G. E., and Olivero, J. J.: Solar backscattered ultraviolet (SBUV) observations of polar mesospheric clouds (PMCs) over two solar cycles, J. Geophys. Res., 108, D8445, doi:10.1029/2002JD002398, 2003.

DeLand, M. T., Shettle, E. P., Thomas, G. E., and Olivero, J. J.: A quarter-century of satellite polar mesospheric cloud observations, J. Atmos. Solar-Terr. Phys., 68, 9-29, doi:10.1016/j.jastp. 2005.08.003, 2006.

Espy, P. J. and Witt, G.: Observation of a quasi 16-day oscillation in the polar summer mesospheric temperature, Geophys. Res. Lett., 23, 1071-1074, doi:10.1029/96GL01068, 1996.

Fiedler, J., Baumgarten, G., von Cossart, G., and Schöch, A.: Lidar observations of temperatures, waves, and noctilucent clouds at $69^{\circ} \mathrm{N}$, in: Society of Photo-Optical Instrumentation Engineers (SPIE) Conference Series, edited by: Schäfer, K. P., Comerón, A., Carleer, M. R., Picard, R. H., and Sifakis, N. I., vol. 5571 of Society of Photo-Optical Instrumentation Engineers (SPIE) Conference Series, pp. 140-151, doi:10.1117/12.564772, 2004.

Fiedler, J., Baumgarten, G., and Lübken, F.-J.: NLC observations during one solar cycle above ALOMAR, J. Atmos. SolarTerr. Phys., available online, in press, doi:10.1016/j.jastp.2008. 11.010, 2009.

Gadsden, M. and Schröder, W.: Noctilucent clouds, SpringerVerlag, New York, 1989.

Garcia, F. J., Taylor, M. J., and Kelley, M. C.: Two-dimensional spectral analysis of mesospheric airglow image data, Appl. Optics, 36, 7374-7385, 1997.

Gerding, M., Höffner, J., Rauthe, M., Singer, W., Zecha, M., and Lübken, F.-J.: Simultaneous observation of noctilucent clouds, mesospheric summer echoes, and temperature at a midlatitude station $\left(54^{\circ} \mathrm{N}\right)$, J. Geophys. Res., 112, D12111, doi:10.1029/ 2006JD008135, 2007.
Gordley, L. L., Hervig, M., Fish III, C., J. M. R., Bailey, S., Cook, J., Hansen, S., Shumway, A., Paxton, G., Deaver, L., Marshall, T., Burton, J., Magill, B., Brown, C., and Kemp, E. T. J.: The Solar Occultation For Ice Experiment (SOFIE), J. Atmos. SolarTerr. Phys., in press, available online, doi:10.1016/j.jastp.2008. 07.012, 2009.

Hansen, G., Serwazi, M., and von Zahn, U.: First detection of a noctilucent cloud by lidar, Geophys. Res. Lett., 16, 1445-1448, 1989.

Hervig, M. E., Gordley, L. L., Stevens, M. H., Russell III, J. M., Bailey, S. M., and Baumgarten, G.: Interpretation of SOFIE PMC measurements: Cloud identification and derivation of mass density, particle shape, and particle size, J. Atmos. Solar-Terr. Phys., in press, available online, doi:10.1016/j.jastp.2008.07. 009, 2009.

Hesstvedt, E.: Note on the Nature of Noctilucent Clouds, J. Geophys. Res., 66, 1985-1987, doi:10.1029/JZ066i006p01985, 1961.

Jesse, O.: Luminous Night-Clouds, Nature, 39, 537, doi:10.1038/ $039537 \mathrm{a} 0,1889$.

Kirkwood, S., Barabash, V., Brändström, B. U. E., Moström, A., Stebel, K., Mitchell, N., and Hocking, W.: Noctilucent clouds, PMSE and 5-day planetary waves: A case study, Geophys. Res. Lett., 29, 1411, doi:10.1029/2001GL014022, 2002.

Lübken, F.-J.: Thermal structure of the arctic summer mesosphere, J. Geophys. Res., 104, 9135-9149, doi:10.1029/1999JD900076, 1999.

McClintock, W. E., Rusch, D. W., Thomas, G. E., Merkel, A. W., Lankton, M., V.A., Drake, Bailey, S. M., and Russell III, J. M.: The Cloud Imaging and Particle Size (CIPS) Experiment on the Aeronomy of Ice in the Mesosphere (AIM) Spacecraft, J. Atmos. Solar-Terr. Phys., available online, in press, doi:10.1016/j.jastp. 2008.10.011, 2009.

Megner, L., Khaplanov, M., Gumbel, J., and Baumgarten, G.: Light scattering by nonspherical ice grains: an application to noctilucent cloud particles, Ann. Geophys., in press, 2009.

Merkel, A. W., Garcia, R. R., Bailey, S. M., and Russell, J. M.: Observational studies of planetary waves in PMCs and mesospheric temperature measured by SNOE and SABER, J. Geophys. Res., 113, D14202, doi:10.1029/2007JD009396, 2008.

Pautet, D. and Moreels, G.: Ground-based satellite-type images of the upper-atmosphere emissive layer, Appl. Optics, 41, 823-831, doi:10.1364/AO.41.000823, 2002.

Rapp, M., Strelnikova, I., Strelnikov, B., Latteck, R., Baumgarten, G., Li, Q., Megner, L., Gumbel, J., Friedrich, M., Hoppe, U.P., and Robertson, S.: First in situ measurement of the vertical distribution of ice volume in a mesospheric ice cloud during the ECOMA/MASS rocket-campaign, Ann. Geophys., 27, 755-766, 2009, http://www.ann-geophys.net/27/755/2009/.

Riggin, D. M., Meyer, C. K., Fritts, D. C., Jarvis, M. J., Murayama, Y., Singer, W., Vincent, R. A., and Murphy, D. J.: MF radar observations of seasonal variability of semidiurnal motions in the mesosphere at high northern and southern latitudes, J. Atmos. Solar-Terr. Phys., 65, 483-493, doi:10.1016/ S1364-6826(02)00340-1, 2003.

Robert, C. E., von Savigny, C., and Burrows, J. P.: Climatology of noctilucent cloud radii and occurrence frequency using SCIAMACHY, J. Atmos. Solar-Terr. Phys., available online, in press, doi:10.1016/j.jastp.2008.10.015, 2009. 
Robertson, S., Horanyi, M., Knappmiller, S., Sternovsky, Z., Holzworth, R., Shimogawa, M., Friedrich, M., Torkar, K., Gumbel, J., Megner, L., Baumgarten, G., Latteck, R., Rapp, M., and Hoppe, U.-P.: Mass analysis of charged aerosol particles in NLC and PMSE during the ECOMA/MASS campaign, Ann. Geophys., in press, 2009.

Russell III, J. M., Bailey, S. M., Horanyi, M., Gordley, L. L., Rusch, D. W., Hervig, M. E., Thomas, G. E., Randall, C. E., Siskind, D. E., Stevens, M. H., Summers, M. E., Taylor, M. I., Englert, C. R., Espy, P. J., McClintock, W. E., and Merkel, A. W.: Aeronomy of Ice in the Mesosphere (AIM): Overview and early science results, J. Atmos. Solar-Terr. Phys., available online, in press, doi:10.1016/j.jastp.2008.08.011, 2009.

Singer, W., Bremer, J., Weiß, J., Hocking, W., Höffner, J., Donner, M., and Espy, P.: Meteor radar observations at middle and arctic latitudes - Part 1: Mean temperatures, J. Atmos. Solar-Terr. Phys., 66, 607-616, doi:10.1016/j.jastp.2004.01.012, 2004.

Thomas, G. E.: Solar Mesosphere Explorer measurements of polar mesospheric clouds (noctilucent clouds)., J. Atmos. Terr. Phys., 46, 819-824, 1984. von Savigny, C., Kokhanovsky, A., Bovensmann, H., Eichmann, K.-U., Kaiser, J., Noël, S., Rozanov, A. V., Skupin, J., and Burrows, J. P.: NLC detection and particle size determination: first results from SCIAMACHY on ENVISAT, Adv. Space Res., 34, 851-856, doi:10.1016/j.asr.2003.05.050, 2004.

von Savigny, C., Robert, C., Bovensmann, H., Burrows, J. P., and Schwartz, M.: Satellite observations of the quasi 5-day wave in noctilucent clouds and mesopause temperatures, Geophys. Res. Lett., 34, L24808, doi:10.1029/2007GL030987, 2007.

von Zahn, U., von Cossart, G., Fiedler, J., Fricke, K. H., Nelke, G., Baumgarten, G., Rees, D., Hauchecorne, A., and Adolfsen, K.: The ALOMAR Rayleigh/Mie/Raman lidar: objectives, configuration, and performance, Ann. Geophys., 18, 815-833, 2000, http://www.ann-geophys.net/18/815/2000/.

Witt, G.: Height, structure and displacements of noctilucent clouds, Tellus, 14, 1-18, 1962. 